\title{
Substitution of peat with municipal solid waste compost in watermelon seedling production combined with fertigation
}

\author{
Maria Papamichalaki ${ }^{1}$, Anastasia Papadaki ${ }^{1}$, and Nikos Tzortzakis ${ }^{2 *}$
}

Interest in reusing organic residues as substrate medium in nurseries has increased worldwide as peat availability has been reduced over time. In this study, the effect of fertigation and/or a partial substitution of peat with municipal solid waste compost (MSWC) on the emergence, growth, and nutrition of watermelon (Citrullus lanatus L.) seedlings were tested. The MSWC extracts (MSWC:water at $10^{-1}$ and $10^{-2}$ dilutions) maintained seedling germination. Under nursery conditions, six media prepared from commercial peat and MSWC were further assessed in conjunction with nutrient application as basic fertilizer (BF) or hydro fertilizer (HF). Adding MSWC to the substrate inhibited seed emergence and mean germination time, whereas fertigation maintained seed emergence in 15\% MSWC but decreased in 45\% MSWC. Adding 45\% MSWC reduced seedling height, leaf number, and fresh weight. The HF increased fresh weight (up to 44\%) and growth in seedlings cultivated in 15\% MSWC. Leaf photosynthetic rate and stomatal conductance increased (up to 2.6-fold) in MSWC-based (<45\% MSWC) substrates, but no differences were observed in chlorophyll a, chlorophyll b, total carotenoid content, and leaf fluorescence. The HF reduced chlorophyll a and total carotenoids, but increased chlorophyll b content. The K, N, and $\mathrm{Na}$ content increased (ranging from 2- to 5-fold) when adding MSWC, whereas P content did not differ. Fertigation benefits seedling nutritive status. Low content (15\% to 30\%) of MSWC may act as an alternative substitute for peat with more positive effects if minerals are provided through HF.

Key words: Citrullus lanatus, compost, growth, municipal solid waste, peat, seed emergence, watermelon.

\section{INTRODUCTION}

Peat moss (Sphagnum spp.) is used as the main substrate component for seedling production in containers in southern Europe. However, peat is mainly imported from northern Europe and has recently become more expensive and its properties more variable. The extensive use of peat as a substrate has led growers to consider replacing it in the medium- to long-term (Sterrett, 2001) with alternatives, including organic residues following the composting process (Siminis and Manios, 1990; Castillo et al., 2000). The need to recycle wastes and the increasing environmental pressure against peat extraction leads to increasing interest in the feasibility of substituting peat with organic waste and by-products. A number of potential alternatives have been identified (Abad et al., 2001) and composts obtained from different organic materials have proven promising (Sanchez-Monedero et

\footnotetext{
${ }^{1}$ Technological Educational Institute of Crete, School of Agricultural and Food Technology, Stauromenos PC 71004, Heraklion, Greece. ${ }^{2}$ Cyprus University of Technology, Faculty of Geotechnical Sciences and Environmental Management, 3603 Limassol, Cyprus. *Corresponding author (nikolaos.tzortzakis@cut.ac.cy).

Received: 11 December 2013.

Accepted: 25 July 2014.

doi: $10.4067 / \mathrm{S} 0718-58392014000400012$
}

al., 2004; Lazcano et al., 2009). However, using compost as a substrate component can cause some problems as a consequence of its high salt content (Castillo et al., 2004), unsuitable physical properties (i.e., porosity), and variable quality and composition (Hicklenton et al., 2001). The correct amounts of compost have to be determined to improve plant growth (Castillo et al., 2000; Ribeiro et al., 2007; Do and Scherer, 2013). In some cases, mixtures of compost and perlite can be used as substrates with no need for additional mineral fertilizer (Castillo et al., 2004).

It is suggested that municipal solid waste compost (MSWC) applied in field trials as an organic soil additive can be used in agricultural production to improve soil physicochemical properties, increase water retention, and supply a considerable amount of essential nutrients (McConnell et al., 1993; Civeira, 2010; Giannakis et al., 2011; Tzortzakis et al., 2012a; Chrysargyris et al., 2013). Municipal solid waste is approximately $60 \%$ to $90 \%$ biodegradable and could be used as bulking material to absorb excess water and supply a useful raw product for the horticultural industry (Mami and Peyvast, 2010). Herrera et al. (2008) reported that urban waste compost can be used for tomato (Solanum lycopersicum L.) transplant production. Several studies have recently indicated the increased interest for using MSWC as an alternative to peat for nursery production of horticultural crops (Castillo et al., 2004; Tzortzakis et al., 2012b; Chrysargyris et al., 
2013; Do and Scherer, 2013). Moreover, most studies have focused on ornamental potted plants, woody shrubs, and trees (Fitzpatrick et al., 1998). For each compost, the appropriate amounts for particular plant growth need to be found because there is no standard growing medium recommended for all crops grown in containers under all growing conditions.

A previous study showed that the growth and development of nursery-produced tomato seedlings using a peat+MSWC mixture was similar to that obtained with the standard peat mixture (Castillo et al., 2004). The present study sought to evaluate the effect of varying the proportion of MSWC mixed with conventional peat substrates as a growth medium in the nursery production of watermelon seedlings.

\section{MATERIALS AND METHODS}

\section{Seed and municipal solid waste compost source}

Watermelon (Citrullus lanatus L. 'Crimson') seeds were purchased from the Agrimore company (Agrimore S.A., Thessaloniki, Greece). Municipal solid waste compost was provided by the Inter-Municipal Enterprise for the Management of Solid Wastes based in Chania, Greece. Compost was made from the organic fraction of selectively collected urban waste and arranged in $5 \mathrm{~m}$ wide $\times 2.5 \mathrm{~m}$ high $\times 45 \mathrm{~m}$ long piles which were regularly turned and watered during a 5- to 6-mo period to ensure appropriate composting conditions (turned windrow system). Sixty percent of compost consisted of particles with $<4 \mathrm{~mm}$ size. The main physicochemical characteristics (dry weight: DW) of compost have been previously described (Tzortzakis et al., 2012a). Characteristics of compost were as follows: $\mathrm{pH}$ : 7.7; electrical conductivity (EC): $17.9 \mathrm{dS} \mathrm{m}^{-1}(1: 1 \mathrm{v} / \mathrm{v})$; ashes: $50.1 \% \mathrm{DW}$; organic matter (OM): 49.9\% DW; organic C: $27.2 \% \mathrm{DW}$; : 1.9\% DW; ratio $\mathrm{C} / \mathrm{N}$ : $7.1 ; 164 \mu \mathrm{g} \mathrm{P} \mathrm{g}^{-1} ; 727 \mu \mathrm{g} \mathrm{g} \mathrm{g}^{-1} ; 403 \mu \mathrm{g} \mathrm{Na} \mathrm{g}{ }^{-1}$, under low limits for heavy metal content.

\section{MSWC extracts and in vitro germination studies}

Municipal solid waste compost extracts were obtained with a 2-L capacity plastic container which was filled with MSWC:water (1:1.5) and shaken for $24 \mathrm{~h}$ at room temperature. The $\mathrm{EC}$ and $\mathrm{pH}$ of the MSWC extract were evaluated with a portable $\mathrm{EC} / \mathrm{pH}$-meter. The MSWC extract was diluted in ratios of 1:0, 1:10, 1:100, 1:1000, 1:10 000, and 1:100 000 (MSWC:water at $10^{-0}$ up to $10^{-6}$ dilutions). For germination tests, air-dried watermelon seeds were placed in Petri dishes with filter paper (four replicates per treatment, 25 seeds per replicate) in a completely randomized design under laboratory conditions (average temperatures: $24.1 \pm 2.1{ }^{\circ} \mathrm{C} \max$, $21.2 \pm 2.4{ }^{\circ} \mathrm{C} \mathrm{min}$ ) and monitored daily. Filter papers were moistened daily with aliquots of diluted MSWC extract for the six treatments. Control treatments (plates) were moisturized with $\mathrm{dH}_{2} \mathrm{O}$. Seeds were considered to be germinated at radicle emergence. Mean shoot and root length was evaluated on the sixth day.

\section{Substrate nutritional status}

Nutritional properties of commercial peat-P and municipal solid waste compost- $\mathrm{C}$ mixtures were examined in three replicates. Organic matter content was determined (ashed at $550{ }^{\circ} \mathrm{C}$ for $8 \mathrm{~h}$ ) and organic $\mathrm{C}$ calculated. The EC and $\mathrm{pH}$ were determined according to the $1: 1$ dilution method. After a hydrochloric digestion of the sample ash, nutrient analysis for $\mathrm{K}$ and $\mathrm{Na}$ (photometer PEP7, Jenway, Dunmow, UK), P (spectrophotometer; Pye Unicam Hitachi U-1100, Tokyo, Japan) was performed, whereas total $\mathrm{N}$ was determined by the Kjeldahl method.

Germination and plant growth studies in nursery tests A mixture of commercial peat (Professional peat, Gebr. Brill Substrate GmbH \& Co. KG, Georgsdorf, Germany), perlite (Perloflor, Protectivo EPE, Athens, Greece), and MSWC was used at different ratios to create six treatments $(\% \mathrm{v} / \mathrm{v})$ : 1) peat:MSWC (100:0) as control, 2) peat:MSWC $(85: 15), 3)$ peat:MSWC (70:30), 4) peat:MSWC (55:45), 5) peat:MSWC (40:60), and 6) peat:MSWC $(0: 100)$. To examine the beneficial effects of fertigation on seedling development, low MSWC (15\%) and high MSWC (45\%) content was combined with or without fertigation. Four additional treatments were therefore created 7) peat:MSWC (85:15) with basic fertilizer (BF), 8) peat:MSWC (55:45) with BF, 9) peat:MSWC (85:15) with weekly hydro fertilizer (HF), 10) peat:MSWC $(55: 45)$ with HF. The BF was applied $\left(1.5 \mathrm{~kg} \mathrm{~m}^{-3}\right)$ once before sowing and HF (20-20-20) was applied on a weekly basis. In each substrate medium, $10 \%$ perlite was added for adequate substrate aeration.

Watermelon seeds were sown $(0.5 \mathrm{~cm}$ depth; 1.0 to $1.5 \mathrm{~cm}$ between seeds in black plastic seedling trays (five seeds per well; four wells per replicate; five replicates per treatment, $40 \mathrm{~cm}^{3}$ well capacity) on the surface of the medium. The experiment was a completely randomized design carried out in an unheated glasshouse (temperature: $25.7 \pm 6.3^{\circ} \mathrm{C} \max , 15.3 \pm 5.1{ }^{\circ} \mathrm{C} \min ; \mathrm{RH}(\%): 93.3 \pm 1.8$ $\max , 74.7 \pm 4.4 \mathrm{~min}$ ) with a mist system for alternate-day watering (initially with $1 \mathrm{~min} / 2 \mathrm{~h}$ and then up to $1 \mathrm{~min} / 5 \mathrm{~h}$ ).

No fertilizer was applied during the growth period in the nursery; seedling nutritional requirements were thus met entirely by the substrates. Daily observations were recorded for seed germination (seeds were recorded as emerged when the hypocotyls appeared above the surface of the substrate medium). Seedlings were thinned to single plant (20 seedlings per treatment) $12 \mathrm{~d}$ after seeding with a 4 to $5 \mathrm{~cm}$ between seedlings. Mean germination time (MGT) was calculated according to Labouriau (1983):

$$
\mathrm{T}=\frac{\sum_{n i \cdot t i}}{n}(\mathrm{~d})
$$

where $T$ is the mean germination time, $t i$ is the given time interval, $n i$ is the number of germinated seeds 
during a given time interval, and $n$ is the total number of germinated seeds.

After $28 \mathrm{~d}$, seedling growth was assessed by harvesting six seedlings per treatment. Seedlings were harvested above substrate, leaf number and height $(\mathrm{cm})$ per seedling was measured from the substrate surface, stem diameter (mm) was measured below the cotyledon node, upper fresh weight $(\mathrm{g})$, total DM content (\%), and chlorophyll a (Chla) ( $\left.\mu \mathrm{g} \mathrm{g}^{-1} \mathrm{fw}\right)$, chlorophyll b (Chlb), and total carotenoid (Car) content were determined according to Porra (2002). Leaf fluorescence was determined (chlorophyll fluorometer OS-30p, Opti-Sciences, Hudson, New Hampshire, USA) and leaf photosynthetic rate $\left(P_{n}\right)$, stomatal conductance $\left(g_{s}\right)$, and internal leaf concentration of $\mathrm{CO}_{2}\left(c_{i}\right)$ were measured with a portable infrared gas analyzer (model Li-6200, Li-Cor, Lincoln, Nebraska, USA). Measurements were taken between 09:00 and 11:10 h, leaf temperature in the chamber was $28 \pm 2{ }^{\circ} \mathrm{C}$, and photosynthetic photon flux density was $1300 \mu \mathrm{mol}$ $\mathrm{m}^{-2} \mathrm{~s}^{-1}$ at the ambient $\mathrm{CO}_{2}$ concentration. The $\mathrm{Li} 6200$ was equipped with a leaf chamber with constant area inserts $\left(6.0 \mathrm{~cm}^{2}\right)$. All gas exchange measurements started $3 \mathrm{~h}$ after the onset of the photoperiod and were replicated in nine plants for each treatment and on two fully-expanded, healthy, sun-exposed leaves per plant.

Leaf elemental analysis for $\mathrm{K}, \mathrm{P}, \mathrm{Na}$, and $\mathrm{N}$ was performed at the end of the experiments.

\section{Statistical analysis}

Experiments were carried out twice. Percentage data were log-transformed before analysis. Data were tested for normality and then subjected to ANOVA. For each of the two experiments (a) in Petri dishes and (b) seedling trays, a two-way ANOVA model was fitted to seed germination/ emergence data using the aov command in R 2.14.2 ( $\mathrm{R}$ Development Core Team, 2006). Substrate, time, and their interaction, SubstratexTime, were set as explanatory variables. Significant differences between mean values were determined by Duncan's Multiple Range test following one-way ANOVA. Statistical analyses were performed with SPSS (SPSS, Chicago, Illinois, USA).

\section{RESULTS}

\section{In vitro seed germination and emergence time}

The first germination was observed after $1 \mathrm{~d}$, whereas final germination was obtained before $7 \mathrm{~d}$. Substrate $\left(\mathrm{F}_{6,147}=160.576, \mathrm{P}<0.001\right)$, time $\left(\mathrm{F}_{6,147}=243.458, \mathrm{P}<\right.$ $0.001)$, and their interaction $\left(\mathrm{F}_{36,147}=9.203, \mathrm{P}<0.001\right)$ all had a significant effect on seed germination. Seed germination decreased in concentrated extracts until the third day, whereas seed germination was finally (on day 7) maintained when MSWC extract at $10^{-1}$ to $10^{-2}$ concentrations were used to compare with the control (water) treatment (Figure 1). However, when pure $\left(10^{-0}\right.$ concentration) extract was used, seed germination was
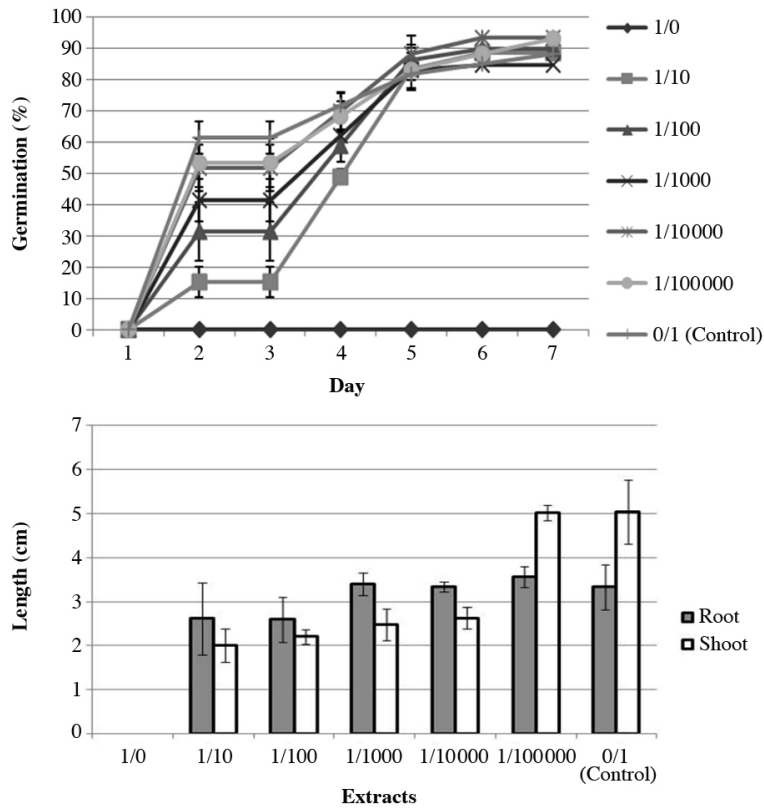

Figure 1. Effects of municipal solid waste compost extracts at concentrations $\left(10^{0}-10^{-6}\right)$ on cumulative seed germination and shoot and root length of watermelon in vitro. Values represent mean $( \pm S E)$ of measurements taken in four Petri dishes $(25$ seeds and five radicles per dish) per treatment.

completely inhibited. Linear regression analysis revealed that seed germination is correlated $(64.8 \%)$ with MSWC extract over time $\left[\mathrm{R}^{2}=0.81 ; p<0.0005 ; \mathrm{Y}=-31.86+\right.$ 8.21 (MSWC extract) +12.32 (time) $]$. The MSWC extract maintained shoot length at concentrations of $10^{-6}$ and reduced shoot length at $10^{-1}$ to $10^{-5}$ of germinated seeds compared with the water treatment, whereas pure MSWC extract inhibited germination (Figure 2). No marked differences in root radicle length at concentrations of $10^{-1}$ to $10^{-6}$ of germinated seeds were observed compared with the control.

\section{Substrate properties}

Organic matter, and as a consequence organic $\mathrm{C}$ content, decreased when adding MSWC to the substrate mixtures (Table 1), whereas low values of $\mathrm{C} / \mathrm{N}$ ratio were observed. Particle size of substrates was $<2 \mathrm{~mm}$ for both peat and MSWC. An increased EC observed in MSWC-based substrates affected element (N, K, and $\mathrm{Na}$ ) content as well as increased $\mathrm{pH}$ values. Adding $\mathrm{BF}$ to the substrate further supported medium nutritional status.

\section{In vivo seed germination and emergence time}

The first germination was observed $4 \mathrm{~d}$ after seeding, whereas the first true leaf emerged after $9 \mathrm{~d}$. Peat and MSWC mixture ratios and fertigation affected seed germination/emergence (Figures 2A, 2B). Substrate $\left(\mathrm{F}_{5,1484}=574.429, \mathrm{P}<0.001\right)$, time $\left(\mathrm{F}_{13,1484}=78.131, \mathrm{P}\right.$ $<0.001)$, and their interaction $\left(\mathrm{F}_{65,147}=9.466, \mathrm{P}<0.001\right)$ all had a significant effect on seed emergence. Increasing 

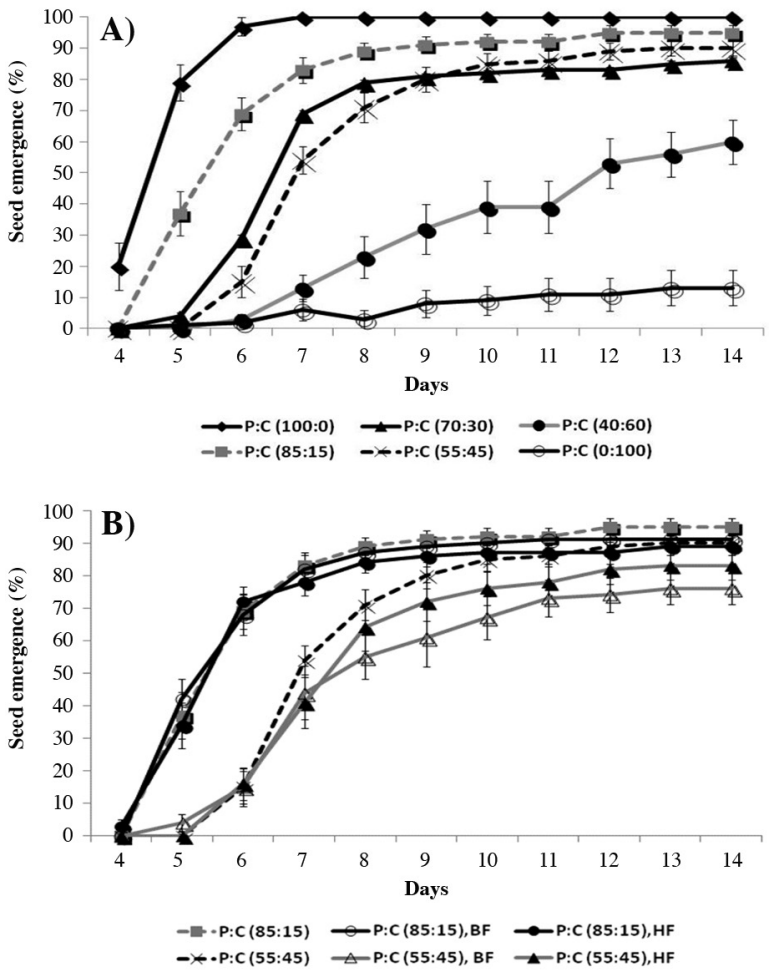

Figure 2. Influence of (A) substrate medium (commercial peat, $\mathbf{P}$; municipal solid waste compost, C) and/or (B) fertigation (basic fertilization, BF; hydro fertilization, HF) on cumulative seedling emergence of watermelon seeds germinated in greenhouse nursery. Values represent mean $( \pm \mathrm{SE})$ of measurements taken in five independent replicates (four wells per replicate; five seeds per well) per treatment.

the MSWC content to the substrate resulted in decreased seed emergence with substantial (up to $40 \%$ and $87 \%$ ) inhibition with $60 \%$ and $100 \%$ MSWC, respectively (Figure 2A). Linear regression analysis revealed that seed emergence is not strongly correlated (48.4\%) with MSWC content over time $\left[\mathrm{R}^{2}=0.69 ; p<0.0005 ; \mathrm{Y}=23.73-\right.$ 11.49 (MSWC content) + 3.41 (time) $]$. When examining the impact of fertigation, seed emergence did not differ in the $85: 15$ peat:MSWC mixture, either with basic or hydro fertilization compared with the relevant control treatment (85:15 peat:MSWC, Figure 2B). Applying fertilizers reduced seed emergence with the highest MSWC content $(45 \%)$.
The ratios of different mixtures affected seed MGT when peat and/or MSWC were used, whereas applying fertilizer did not affect seed MGT (Figures 3A, 3B). Thus, increased MSWC (>30\%) content in the substrate resulted in increased MGT (up to 5-d delay). No differences were observed between 15\% MSWC and the control for watermelon MGT (Figure 3A).

Adding fertilizers to substrates with low MSWC content did not benefit seed germination/emergence, whereas applying fertilizers in high MSWC content substrates reduced seed emergence.

\section{In vivo seedling growth}

The ANOVA showed that adding MSWC to commercial peat significantly reduced (between $29 \%$ and $89 \%$ )
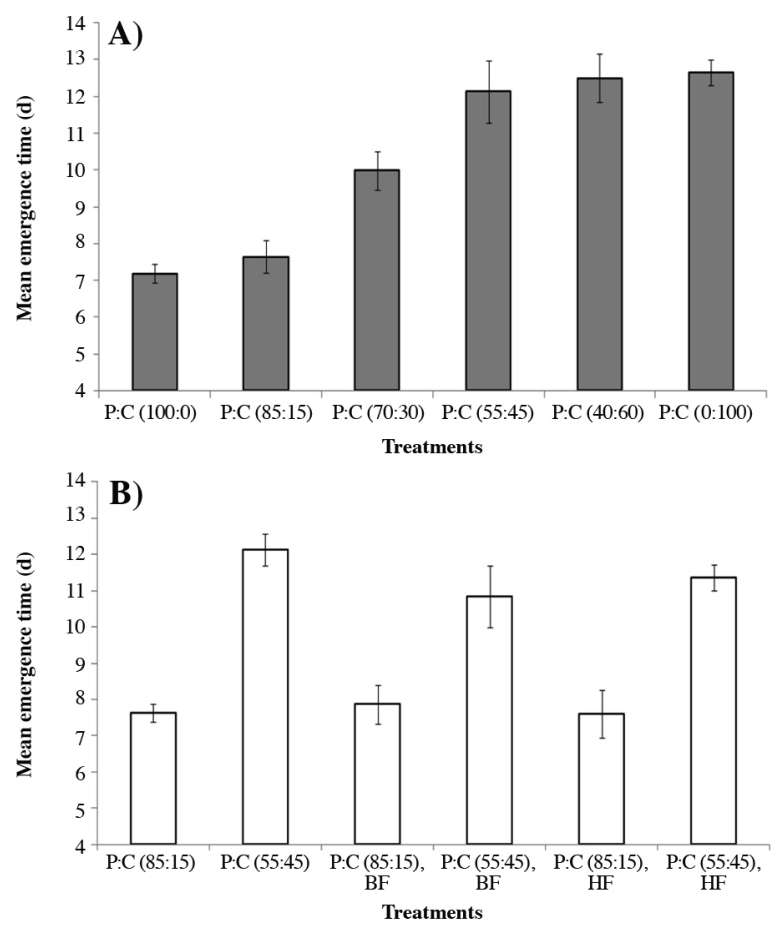

Figure 3. Mean emergence time of watermelon in (A) different substrate medium (commercial peat, $P$; municipal solid waste compost, C) and/or (B) fertigation (basic fertilization, BF; hydro fertilization, HF) under nursery conditions. Values represent mean ( \pm $\mathrm{SE}$ ) of measurements taken in five replicates (four wells per replicate; five seeds per well) per treatment.

Table 1. Nutritional status of different mixtures of commercial peat (P), municipal solid waste compost (C), and fertigation (basic fertilization, BF).

\begin{tabular}{|c|c|c|c|c|c|c|c|c|c|}
\hline & Organic matter & Organic C & $\mathrm{C} / \mathrm{N}$ & $\mathrm{pH}$ & $\mathrm{EC}$ & $\mathrm{N}$ & $\mathrm{K}$ & $\mathrm{P}$ & $\mathrm{Na}$ \\
\hline & \multicolumn{2}{|c|}{$\%$} & & & $\mathrm{dS} \mathrm{m}^{-1}$ & $\longrightarrow$ & 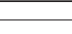 & $\mathrm{mg} \mathrm{g}^{-1}$ & - \\
\hline $\mathrm{P}: \mathrm{C}(100: 0)$ & 89.68 & 49.82 & 14.96 & 5.59 & 1.26 & 3.33 & 0.043 & 0.198 & 0.014 \\
\hline$P: C(85: 15)$ & 69.46 & 38.59 & 10.40 & 6.49 & 3.81 & 3.71 & 0.211 & 0.184 & 0.182 \\
\hline$P: C(70: 30)$ & 59.84 & 33.25 & 6.37 & 6.87 & 8.50 & 5.22 & 0.217 & 0.179 & 0.309 \\
\hline $\mathrm{P}: \mathrm{C}(55: 45)$ & 57.83 & 32.13 & 6.04 & 6.94 & 10.15 & 5.32 & 0.446 & 0.181 & 0.323 \\
\hline$P: C(40: 60)$ & 57.06 & 31.70 & 5.77 & 7.11 & 14.38 & 5.49 & 0.568 & 0.164 & 0.363 \\
\hline $\mathrm{P}: \mathrm{C}(0: 100)$ & 49.91 & 27.02 & 4.73 & 7.72 & 17.94 & 5.71 & 0.727 & 0.154 & 0.403 \\
\hline $\mathrm{P}: \mathrm{C}(85: 15), \mathrm{BF}$ & 71.32 & 39.62 & 9.83 & 6.55 & 5.12 & 4.03 & 0.442 & 0.263 & 0.199 \\
\hline $\mathrm{P}: \mathrm{C}(55: 45), \mathrm{BF}$ & 53.86 & 29.92 & 5.05 & 7.29 & 10.91 & 5.92 & 0.754 & 0.214 & 0.319 \\
\hline
\end{tabular}


seedling height and stem diameter (Table 2). Leaf number was reduced (up to $73 \%$ ) with MSWC (> 45\%), whereas stem diameter was reduced only in the case of pure $(100 \%)$ MSWC used as substrate. Interestingly, low (15\% to $30 \%$ ) MSWC content significantly increased (up to 28\%) plant fresh weight compared with plants grown in peatbased (control) substrate. No differences were observed in stem diameter regarding different fertilizer applications in low and high MSWC content substrates. Applying both fertigations (BF and $\mathrm{HF}$ ) increased leaf number or maintained plant height in plants grown in $15 \%$ MSWC. Hydro fertigation increased (up to $44 \%$ ) fresh weight in seedlings grown in $15 \%$ MSWC substrate, whereas BF increased DM content for the same treatment. No marked effects for the highest MSWC content (45\%) were obtained combined with fertigation, either as basic or hydro fertilizer.

In the case of different MSWC contents, adding MSWC (15\% to $45 \%)$ to the substrate increased (2.6-fold) photosynthetic rate and leaf stomatal conductance with higher values at $45 \%$ MSWC (Table 3 ). Additionally, the leaf internal $\mathrm{CO}_{2}$ concentration was significantly higher

Table 2. Impact of fertigation (basic fertilization, BF; hydro fertilization, HF) and substrate medium (commercial peat, P; municipal solid waste compost, C) on seedling height, number of leaves produced, stem diameter, fresh weight, and dry matter content on watermelon seedlings grown in the nursery.

\begin{tabular}{lllllc}
\hline & Height & $\begin{array}{c}\text { Leaf } \\
\text { number }\end{array}$ & $\begin{array}{c}\text { Stem } \\
\text { diameter }\end{array}$ & $\begin{array}{c}\text { Fresh } \\
\text { weight }\end{array}$ & $\begin{array}{c}\text { Dry } \\
\text { matter }\end{array}$ \\
\hline & $\mathrm{cm}$ & & $\mathrm{mm}$ & g plant $^{-1}$ & $\%$ \\
P:C $(100: 0)$ & $34.62 \mathrm{a}$ & $6.82 \mathrm{a}$ & $3.27 \mathrm{a}$ & $4.56 \mathrm{~b}$ & $14.46 \mathrm{a}$ \\
P:C $(85: 15)$ & $24.46 \mathrm{bA}$ & $5.63 \mathrm{aB}$ & $3.39 \mathrm{aA}$ & $5.64 \mathrm{aB}$ & $10.24 \mathrm{bB}$ \\
P:C $(70: 30)$ & $21.47 \mathrm{~b}$ & $6.00 \mathrm{a}$ & $3.10 \mathrm{a}$ & $5.83 \mathrm{a}$ & $11.02 \mathrm{~b}$ \\
P:C $(55: 45)$ & $12.24 \mathrm{cB}$ & $5.16 \mathrm{bB}$ & $3.40 \mathrm{aA}$ & $4.41 \mathrm{bB}$ & $10.52 \mathrm{bB}$ \\
P:C $(40: 60)$ & $5.33 \mathrm{~d}$ & $3.01 \mathrm{c}$ & $3.08 \mathrm{a}$ & $1.96 \mathrm{c}$ & $7.38 \mathrm{c}$ \\
P:C $(0: 100)$ & $3.76 \mathrm{~d}$ & $1.83 \mathrm{~d}$ & $0.86 \mathrm{~b}$ & $1.18 \mathrm{c}$ & $8.00 \mathrm{c}$ \\
P:C $(85: 15), \mathrm{BF}$ & $31.02 \mathrm{~A}$ & $6.33 \mathrm{~A}$ & $2.94 \mathrm{~A}$ & $4.88 \mathrm{~B}$ & $12.49 \mathrm{~A}$ \\
P:C $(55: 45), \mathrm{BF}$ & $14.62 \mathrm{~B}$ & $5.00 \mathrm{~B}$ & $3.68 \mathrm{~A}$ & $4.33 \mathrm{~B}$ & $9.48 \mathrm{~B}$ \\
P:C $(85: 15), \mathrm{HF}$ & $28.91 \mathrm{~A}$ & $7.50 \mathrm{~A}$ & $3.09 \mathrm{~A}$ & $8.15 \mathrm{~A}$ & $9.97 \mathrm{~B}$ \\
P:C $(55: 45), \mathrm{HF}$ & $14.92 \mathrm{~B}$ & $5.33 \mathrm{~B}$ & $3.15 \mathrm{~A}$ & $4.40 \mathrm{~B}$ & $10.42 \mathrm{~B}$
\end{tabular}

Values $(n=6)$ in columns followed by the same lowercase letter are not significantly different $(P \leq 0.05)$ for substrate medium, and values in columns followed by the same uppercase letter are not significantly different $(P \leq 0.05)$ for fertigation impact. in $100 \%$ MSWC compared with other treatments. No differences among treatments (except for 100\% MSWC treatment) were observed in leaf fluorescence (mean 0.74 variable fluorescence/maximal fluorescence $\mathrm{Fv} /$ Fm), as well as Chla content (mean $52.18 \mu \mathrm{g} \mathrm{g}^{-1} \mathrm{fw}$ ). Total carotenoid (mean $20.83 \mu \mathrm{g} \mathrm{g}^{-1} \mathrm{fw}$ ) and Chlb (mean $47.81 \mu \mathrm{g} \mathrm{g}^{-1} \mathrm{fw}$ ) content was similar for seedlings in all studied MSWC ratios. When examining the impact of fertigation, HF reduced Chla and total carotenoid content in low (15\%) and high (45\%) MSWC, but increased Chlb content (Table 3). Both $\mathrm{BF}$ and HF fertigation reduced leaf stomatal conductance and leaf internal $\mathrm{CO}_{2}$ concentration compared with equivalent MSWC controls. No differences were observed in leaf fluorescence (mean $0.79 \mathrm{Fv} / \mathrm{Fm}$ ) and leaf photosynthetic rate fluorescence (mean $16.72 \mu \mathrm{mol} \mathrm{m} \mathrm{m}^{-2} \mathrm{~s}^{-1}$ ) among treatments.

Leaf element content was affected by the MSWC compost ratio in the substrate. Leaf content increased for $\mathrm{N}$ (2-fold), K (2-fold), and $\mathrm{Na}$ (5-fold) by adding MSWC compared with the control (peat-based) substrate. No differences (mean $0.010 \mathrm{mg} \mathrm{g}^{-1} \mathrm{fw}$ ) were observed in $\mathrm{P}$ content among seedlings grown in substrates with different MSWC contents.

When examining the impact of fertigation in seedling leaf elemental content, $\mathrm{N}$ content increased in the case of $15 \%$ MSWC for both HF and BF applications compared with the relevant control treatments, whereas $\mathrm{K}$ content increased in $15 \%$ MSWC combined with BF (Table 4). Sodium content increased in $45 \%$ MSWC, whereas HF or BF fertigation had no relevant effects. However, when $\mathrm{BF}$ fertigation was applied in 15\% MSWC, Na content increased compared with the control and HF fertigation. No differences were observed in $\mathrm{P}$ content among seedlings grown in substrates with different MSWC content and/or fertigation enrichment.

\section{DISCUSSION}

Results confirm the favorable influence of MSWC in partial peat replacement and show that low MSWC

Table 3. Impact of fertigation (basic fertilization, BF; hydro fertilization, HF) and substrate medium (commercial peat, P; municipal solid waste compost, $\mathrm{C}$ ) on leaf fluorescence, chlorophyll a (Chla), chlorophyll b (Chlb), total carotenoids $\left(\right.$ Car), leaf photosynthetic rate $\left(P_{n}\right)$, leaf stomatal conductance $\left(g_{s}\right)$, and leaf internal $\mathrm{CO}_{2}$ concentration $\left(c_{i}\right)$ on watermelon seedlings grown in the nursery.

\begin{tabular}{|c|c|c|c|c|c|c|c|}
\hline & Fluorescence & Chla & Chlb & Car & $P_{n}$ & $\mathrm{~g}_{\mathrm{s}}$ & $\mathrm{c}_{\mathrm{i}}$ \\
\hline & $\mathrm{Fv} / \mathrm{Fm}$ & 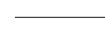 & $\mu \mathrm{g} \mathrm{g}^{-1}$ fw & & \multicolumn{2}{|c|}{$\longrightarrow \mu \mathrm{mol} \mathrm{m}{ }^{-2} \mathrm{~s}^{-1} \longrightarrow$} & $\mu \mathrm{mol} \mathrm{mol}{ }^{-1}$ \\
\hline P:C (100:0) & $0.72 \mathrm{a}$ & $51.80 \mathrm{ab}$ & $48.27 \mathrm{a}$ & $19.71 \mathrm{a}$ & $6.68 \mathrm{c}$ & $0.065 \mathrm{~d}$ & $202.9 \mathrm{~b}$ \\
\hline$P: C(85: 15)$ & $0.78 \mathrm{aA}$ & $53.01 \mathrm{aA}$ & $53.33 \mathrm{aB}$ & $22.32 \mathrm{aA}$ & $14.74 \mathrm{aA}$ & $0.180 \mathrm{aA}$ & $201.2 \mathrm{bA}$ \\
\hline P:C (70:30) & $0.77 \mathrm{a}$ & $52.32 \mathrm{ab}$ & $56.96 a$ & $21.11 \mathrm{a}$ & $16.04 \mathrm{a}$ & $0.210 \mathrm{a}$ & $199.4 b$ \\
\hline$P: C(55: 45)$ & $0.78 \mathrm{aA}$ & $52.81 \mathrm{aA}$ & $53.19 \mathrm{aB}$ & $22.36 \mathrm{aA}$ & $17.46 \mathrm{aA}$ & $0.156 \mathrm{abA}$ & $173.2 \mathrm{bA}$ \\
\hline P:C (40:60) & $0.65 \mathrm{a}$ & $53.02 \mathrm{a}$ & $54.07 \mathrm{a}$ & $21.47 \mathrm{a}$ & $12.73 b$ & $0.132 b$ & $212.3 \mathrm{~b}$ \\
\hline$P: C(0: 100)$ & $0.13 b$ & $50.12 b$ & $51.02 \mathrm{a}$ & $18.04 \mathrm{a}$ & $6.01 \mathrm{c}$ & $0.110 \mathrm{c}$ & $344.1 \mathrm{a}$ \\
\hline $\mathrm{P}: \mathrm{C}(85: 15), \mathrm{BF}$ & $0.77 \mathrm{~A}$ & $51.32 \mathrm{AB}$ & $58.80 \mathrm{~B}$ & $19.12 \mathrm{AB}$ & $15.75 \mathrm{~A}$ & $0.106 \mathrm{~B}$ & $127.5 \mathrm{~A}$ \\
\hline $\mathrm{P}: \mathrm{C}(55: 45), \mathrm{BF}$ & $0.80 \mathrm{~A}$ & $53.11 \mathrm{~A}$ & $53.75 \mathrm{~B}$ & $22.46 \mathrm{~A}$ & $16.82 \mathrm{~A}$ & $0.091 \mathrm{~B}$ & $102.8 \mathrm{~B}$ \\
\hline $\mathrm{P}: \mathrm{C}(85: 15), \mathrm{HF}$ & $0.82 \mathrm{~A}$ & $49.92 \mathrm{~B}$ & $70.26 \mathrm{~A}$ & $15.17 \mathrm{~B}$ & $17.43 \mathrm{~A}$ & $0.093 \mathrm{~B}$ & $106.6 \mathrm{~B}$ \\
\hline $\mathrm{P}: \mathrm{C}(55: 45), \mathrm{HF}$ & $0.82 \mathrm{~A}$ & 48.41B & $72.57 \mathrm{~A}$ & $13.71 \mathrm{~B}$ & $18.13 \mathrm{~A}$ & $0.060 \mathrm{~B}$ & $98.5 \mathrm{~B}$ \\
\hline
\end{tabular}

Values $(\mathrm{n}=6)$ in columns followed by the same lowercase letter are not significantly different $(P \leq 0.05)$ for substrate medium, and values in columns followed by the same uppercase letter are not significantly different $(P \leq 0.05)$ for fertigation impact.

Fv: variable fluorescence, Fm: maximal fluorescence. 
content can substitute peat and be used for watermelon seedling production under nursery conditions. The MSWC extracts maintained seed emergence, whereas pure $\left(10^{-0}\right.$ concentration) extract completely inhibited seed germination; this can be attributed to high EC and $\mathrm{pH}$ values of MSWC extract (1:1.5 v/v; EC: $11.21 \mathrm{dS} \mathrm{m}^{-1}$; $\mathrm{pH}$ : 6.87). As a consequence, substrate, time, and their interaction all had a significant effect on seed germination. It was reported in previous studies that there was no inhibition of germination in the case of cucumber seeds in relation to the control treatment when MSWC: water extracts were used (Pal and Bhattacharyya, 2003); this is in accordance with the findings of the present study. Recent findings revealed that MSWC can enhance melon seed germination at $10^{-2}$ to $10^{-6}$ extract concentrations (Chrysargyris et al., 2013).

The MSWC extract $\left(10^{-1}\right.$ to $\left.10^{-5}\right)$ reduced shoot length of germinated seeds; this agrees with previous studies when olive mill waste extracts were used for seed priming procedures in lettuce and radish (Kelepesi and Tzortzakis, 2009). Moreover, in pure or highly concentrated MSWC extracts, severe suppression of root length and shoot length were observed with cucumber seeds treated with 1:7.5 MSWC:water extracts (Pal and Bhattacharyya, 2003), whereas pure MSWC extract in the current study completely inhibited germination (Figure 2). The stimulatory effects of MSWC extract on seed germination can help early seed germination by providing higher competitive ability (Zhang and Maun, 1990) and reducing losses in seedling propagation.

The $\mathrm{C} / \mathrm{N}$ ratio is widely used as an indicator of $\mathrm{OM}$ maturity and stability. The low value of the $\mathrm{C} / \mathrm{N}$ ratio in MSWC used in the present study suggested that composts were stable and mature according to Davidson et al. (1994), who reported that composts with a $\mathrm{C} / \mathrm{N}$ ratio $<20$ are ideal for nursery plant production. Ratios $>30$ can be toxic and cause plant death (Zucconi et al., 1981). In the present study, OM decreased when MSWC was added to the substrate mixtures (Table 1), which is mainly due to the decreased income from peat as OM. Adding BF to the substrate further supported medium nutritional status as measured by increased EC and element content.

The mixture ratios affected seed germination/ emergence when peat and MSWC, as well as fertigation were used (Figures 2A, 2B). Substrate, time, and their interaction all had a significant effect on seed emergence as a result of the substrate nutrient released over time due to increased substrate EC. Increasing MSWC content in the substrate resulted in decreased seed emergence, which contrasts with previous studies in basil (Ocimum basilicum L.) seedlings (Tzortzakis et al., 2012b) and is probably due to the different plant species. When adding fertilizers to substrates with low MSWC content, seed germination/emergence was not benefited; this highlights the increased nutritional value of MSWC, whereas applying fertilizers in high MSWC content substrates reduced seed emergence possibly due to excess nutrition that forced increased osmotic or phytotoxic levels. It is well documented that the stimulation of several seed pre-sowing treatments (halopriming, hydropriming, osmopriming, thermopriming, solid matrix priming, and biopriming as reported by Ashraf and Foolad 2005) compared with untreated seeds could alter embryo physiology and enzyme activation; therefore, developmental processes occur more rapidly after sowing (Kattimani et al., 1999). Increased MSWC (> 30\%) content in the substrate resulted in increased MGT, which is in accordance with previous studies employing MSWC in melon seed emergence (Chrysargyris et al., 2013); on the other hand, low MSWC (15\%) content did not differ with the control for watermelon MGT (Figure 3A).

Although there is no ideal, single, growth medium for nursery-produced horticultural crops (Bugbee, 1996), most vegetable greenhouse-grown species display better growth at low acid $\mathrm{pH}$ values (5.2 to 7.0); peat mixtures were close to these values, but MSWC were not. Like $\mathrm{pH}$ levels, the highest initial substrate EC values were recorded for mixtures containing MSWC. It has been reported that substrates with high EC values reduce water retention, which negatively affects the imbibing process and can delay seed emergence rates (Ribeiro et al., 2007).

Adding MSWC to commercial peat significantly reduced vegetative growth (seedling height and stem diameter, Table 2) especially in high MSWC content (> $45 \%$ ), which agrees with previous studies in cucumber and melon seedlings (Mami and Peyvast, 2010; Chrysargyris et al., 2013). Interestingly, low (15\% to 30\%) MSWC contents increased plant fresh weight compared with plants grown in peat-based (control) substrate. Fertigation (BF and $\mathrm{HF}$ ) altered, to some extent, the negative effects of MSWC in the substrate vegetative growth with increased leaf number, fresh weight and DM content, or maintained plant height in plants grown in $15 \%$ MSWC with more marked positive effects under the HF application.

Seedlings grown in high content MSWC mixtures displayed worse quality and suitability for transplanting, and this was possibly due to increased EC and/or altered medium physicochemical properties. Seedling resistance to transplant stress is directly related to DM content, which improves seedling establishment in the soil or growth substrate (Pimpini and Gianquinto, 1991).

Adding low MSWC to the substrate benefited plant physiological status with increased photosynthetic rate and leaf stomatal conductance (Table 3) or maintained other variables such as leaf fluorescence, Chla, Chlb, and total carotenoid content. However, fertigation altered some variables such as $\mathrm{HF}$, reduced Chla and total carotenoid content, but increased Chlb content (Table 3), whereas both $\mathrm{BF}$ and $\mathrm{HF}$ fertigation reduced leaf stomatal conductance and leaf internal $\mathrm{CO}_{2}$ concentration compared with equivalent MSWC controls. 
Leaf element content $(\mathrm{N}, \mathrm{K}$, and $\mathrm{Na}$ ) increased the MSWC compost ratio in the substrate, which indicates that the nutritional value of the media confirmed high EC values of MSWC; this agrees with melon seedling production with the same MSWC (Chrysargyris et al., 2013). The $P$ content did not differ among seedlings grown in substrates with different MSWC contents, which was expected given that MSWC is not enriched with P. Adding fertigation further increased $\mathrm{N}$ and $\mathrm{K}$ content of substrates, whereas Na content increased in 45\% MSWC; $\mathrm{HF}$ or BF fertigation have no relevant effects, and this highlights the high Na content of the MSWC medium itself. Thus, considerable nutritional value was noticeable due to the MSWC and fertigation combination in the substrates.

Production of vegetable seedlings, especially in Mediterranean countries with great field and greenhouse crop expansion, is a highly competitive business; uniform and rapid seed emergence is an essential requirement to increase crop yield, quality, and profits. Using good crop substrates is therefore critical (Sterrett, 2001; Lazcano et al., 2009). Transplants, compared with direct sowing, are a more reliable method of ensuring the proper establishment of a range of commercial horticultural crops with high economic value. Additionally, improved methods of selective waste collection and compost processing will enable an increasingly widespread use of this renewable organic compost as an alternative to highquality sphagnum peat, which is non-renewable, less available, and more expensive for growers.

Low content $(<30 \%)$ MSW compost incorporated in peat-based substrates benefits watermelon seedling production combined with fertilizers applied through HF rather than $\mathrm{BF}$. These proportions reduce the negative effects of high $\mathrm{pH}$ and $\mathrm{EC}$ on seedling growth and provide a seedling that is comparable to one obtained using standard peat-based mixtures; this agrees with previous

Table 4. Impact of fertigation (basic fertilization, BF; hydro fertilization, HF) and substrate medium (commercial peat, P; municipal solid waste compost, C) on leaf element concentration in watermelon seedlings grown in the nursery.

\begin{tabular}{|c|c|c|c|c|}
\hline & $\mathrm{N}$ & $\mathrm{K}$ & $\mathrm{P}$ & $\mathrm{Na}$ \\
\hline & \multicolumn{4}{|c|}{$\longrightarrow \mathrm{mg} \mathrm{g}^{-1} \mathrm{fw}$} \\
\hline P:C (100:0) & $5.82 \mathrm{c}$ & $0.118 \mathrm{c}$ & $0.011 \mathrm{a}$ & $0.008 \mathrm{~d}$ \\
\hline $\mathrm{P}: \mathrm{C}(85: 15)$ & $11.09 \mathrm{abB}$ & $0.173 \mathrm{bB}$ & $0.010 \mathrm{aA}$ & $0.010 \mathrm{dC}$ \\
\hline P:C (70:30) & $9.74 b$ & $0.241 \mathrm{a}$ & $0.010 \mathrm{a}$ & $0.023 \mathrm{c}$ \\
\hline$P: C(55: 45)$ & $9.34 \mathrm{bB}$ & $0.216 \mathrm{abB}$ & $0.011 \mathrm{aA}$ & $0.034 \mathrm{bA}$ \\
\hline P:C (40:60) & $11.29 \mathrm{ab}$ & $0.258 \mathrm{a}$ & $0.009 \mathrm{a}$ & $0.038 \mathrm{~b}$ \\
\hline $\mathrm{P}: \mathrm{C}(0: 100)$ & $12.01 \mathrm{a}$ & $0.246 a$ & $0.009 \mathrm{a}$ & $0.043 \mathrm{a}$ \\
\hline $\mathrm{P}: \mathrm{C}(85: 15), \mathrm{BF}$ & $10.42 \mathrm{~B}$ & $0.261 \mathrm{~A}$ & $0.013 \mathrm{~A}$ & $0.019 \mathrm{~B}$ \\
\hline $\mathrm{P}: \mathrm{C}(55: 45), \mathrm{BF}$ & $12.65 \mathrm{~B}$ & $0.203 B$ & $0.011 \mathrm{~A}$ & $0.028 \mathrm{~A}$ \\
\hline $\mathrm{P}: \mathrm{C}(85: 15), \mathrm{HF}$ & $15.51 \mathrm{~A}$ & $0.205 B$ & $0.013 \mathrm{~A}$ & $0.013 \mathrm{C}$ \\
\hline $\mathrm{P}: \mathrm{C}(55: 45), \mathrm{HF}$ & $14.64 \mathrm{~A}$ & $0.227 \mathrm{~B}$ & $0.011 \mathrm{~A}$ & $0.029 \mathrm{~A}$ \\
\hline
\end{tabular}

Values (represent measurements taken in three replicates per treatment: three seedlings mixtures per replicate) in columns followed by the same lowercase letter are not significantly different $(\mathrm{P} \leq 0.05)$ for substrate medium, and values in columns followed by the same uppercase letter are not significantly different $(\mathrm{P} \leq 0.05)$ for fertigation impact. studies in melon, basil, and marigold (Tagetes erecta L.) seedling production (Tzortzakis et al., 2011; 2012b). Similarly, nursery-produced tomato seedlings grown in peat with MSWC (30\%) displayed good quality indices (Vavrina, 1995; Castillo et al., 2004). This is probably due to a correct balance between nutrient supply from MSWC and the physical characteristics of peat, particularly substrate porosity and aeration.

\section{CONCLUSIONS}

Municipal solid waste compost was found to be a suitable alternative component of mixed-peat substrates for watermelon seedlings provided it accounts for less than $30 \%$ of the mixture combined with fertilizers with more positive effects when minerals were provided through hydro fertigation rather than basic fertigation.

\section{LITERATURE CITED}

Abad, M., P. Noguera, and S. Bures. 2001. National inventory of organic wastes for use as growing media for ornamental potted plant production: case study in Spain. Bioresource Technology 77:197-200.

Ashraf, M., and M.R. Foolad. 2005. Pre-sowing seed treatment A shotgun approach to improve germination, plant growth, and crop yield under saline and non-saline conditions. Advances in Agronomy 88:223-271.

Bugbee, G.J. 1996. Growth of Rhododendron, Rudbeckia and Thuja and the leaching of nitrates as affected by the $\mathrm{pH}$ of potting media amended with biosolids compost. Compost Science and Utilization 4:53-59.

Castillo, J.E., F. Herrera, R.J. López-Bellido, F.J. López-Bellido, L. López-Bellido, and E.J. Fernández. 2004. Municipal solid waste (MSW) compost as a tomato transplant medium. Compost Science and Utilization 12:86-92.

Castillo, A.E., S.H. Quarin, and M.C. Iglesias. 2000. Vermicompost chemical and physical characterization from raw and mixed organic wastes. Chilean Journal of Agricultural Research 60:74-79.

Chrysargyris, A., C. Saridakis, and N. Tzortzakis. 2013. Use of municipal solid waste compost as growing medium component for melon seedlings production. Journal of Plant Biology and Soil Health 2:1-5.

Civeira, G. 2010. Influence of municipal solid waste compost on soil properties and plant reestablishment in peri-urban environments. Chilean Journal of Agricultural Research 70:416-425.

Davidson, H., R. Mecklenburg, and C. Peterson. 1994. Nursery management: Administration and culture. $3^{\text {rd }}$ ed. 486 p. Prentice Hall, Englewood Cliffs, New Jersey, USA.

Do, T.C.V., and H.W. Scherer. 2013. Compost as growing media component for salt-sensitive plants. Plant, Soil and Environment 59:214-220.

Fitzpatrick, G.E., E.R. Duke, and K.A. Klock-Moore. 1998. Use of compost products for ornamental crop production: research and grower experiences. HortScience 33:941-944.

Giannakis, G., N.N. Kourgialas, N.V. Paranychianakis, N.P. Nikolaidis, and N. Kalogerakis. 2011. Effects of solid waste compost on vegetables growth and metals accumulation. p. 42-48 $5^{\text {th }}$ European Bioremediation Conference in Chania, Greece. 4-7 July. Technical University of Crete, Crete, Greece.

Herrera, F., J.E. Castillo, A.F. Chica, and L. López Bellido. 2008. Use of municipal solid waste compost (MSWC) as a growing medium in the nursery production of tomato plants. Bioresource Technology 99:287-296. 
Hicklenton, P.R., V. Rodd, and P.R. Warman. 2001. The effectiveness and consistency of source-separated municipal solid waste and bark composts as components of container growing media. Scientia Horticulturae 91:349-363.

Kattimani, K.N., Y.N. Reddy, and R.B. Rao. 1999. Effect of presoaking seed treatment on germination, seedling emergence, seedling vigour and root yield of Ashwagandha (Withania somnifera Daunal.) Seed Science and Technology 27:483-488.

Kelepesi, S., and N.G. Tzortzakis. 2009. Olive-mill wastes - A growing medium component for seedling and crop production of lettuce and chicory. International Journal of Vegetable Science $15: 325-339$

Labouriau, L.G. 1983. A germinação das sementes. 174 p. Secretaria Geral da Organização dos Estados Americanos, Washington D.C., USA.

Lazcano, C., J. Arnold, A. Tato, J.G. Zaller, and J. Dominguez. 2009. Compost and vermicompost as nursery pot components: effects on tomato plant growth and morphology. Spanish Journal of Agricultural Research 7:944-951.

Mami, Y., and G. Peyvast. 2010. Substitution of municipal solid waste compost for peat in cucumber transplant production. Journal of Horticulture and Forestry 2:157-160.

McConnell, D.B., A. Shiralipour, and W. Smith. 1993. Compost application improves soil properties. Biocycle 34:61-63.

Pal, R., and P. Bhattacharyya. 2003. Effect of municipal solid waste compost on seed germination of rice, wheat and cucumber. Archives of Agronomy and Soil Science 49:407-414.

Pimpini, F., e G. Gianquinto. 1991. Primi resultati sulle modalita di allevamento invivaio di piantina di pomodoro da industria. Riflessi su aecrescimento e produzione in campo. $2^{\circ}$ Convegno Nazionale II vivaismo orticolo, Foggia, Italia. 2-4 maggio. Camera di Commercio Industria Artigianato e Agricoltura Foggia, Istituto di Meccanica Agraria Università Degli Studi di Bari Aldo Moro, Bari, Italia.

Porra, R.J. 2002. The chequered history of the development and use of simultaneous equations for the accurate determination of chlorophylls $a$ and $b$. Photosynthesis Research 73:149-156.
R Development Core Team. 2006. R: a language and environment for statistical computing. R Foundation for Statistical Computing, Vienna, Austria.

Ribeiro, H.M., A.M. Romero, H. Pereira, P. Borges, F. Cabral, and E. Vasconcelos. 2007. Evaluation of a compost obtained from forestry wastes and solid phase of pig slurry as a substrate for seedlings production. Bioresource Technology 98:3294-3297.

Sanchez-Monedero, M.A., A. Roig, J. Cegarra, M.P. Bernal, P. Noguera, M. Abad, et al. 2004. Composts as media constituents for vegetable transplant production. Compost Science and Utilization 12:161-168.

Siminis, H.I., and V.L. Manios. 1990. Mixing peat with MSW compost. BioCycle 31:60-61.

Sterrett, S.B. 2001. Compost as horticultural substrates for vegetable transplant production p. 227-240. In Stoffella, P.J., and B.A. Kahn (eds.) Compost utilization in horticultural cropping systems. Lewis Publication, Boca Raton, Florida, USA.

Tzortzakis, N., E. Dagianta, G. Daskalakis, V. Manios, C. Paterakis, and T. Manios. 2011. Municipal solid waste compost: A growing medium component for melon seedling production. p. 1-6. $5^{\text {th }}$ European Bioremediation Conference, Chania, Greece. 4-7 July. Technical University of Crete, Crete, Greece.

Tzortzakis, N., S. Gouma, E. Dagianta, C. Saridakis, M. Papamichalaki, D. Goumas, et al. 2012a. Use of fertigation and municipal solid waste compost for greenhouse pepper cultivation. The Scientific World Journal doi:10.1100/2012/973193.

Tzortzakis, N., S. Gouma, C. Paterakis, and T. Manios. 2012b. Deployment of municipal solid wastes as a substitute growing medium component in marigold and basil seedlings production. The Scientific World Journal doi:10.1100/2012/285874.

Vavrina, C. 1995. Municipal solid waste materials as soilless media for tomato transplant production. Proceedings of the Florida State Horticultural Society 108:232-234.

Zhang, J., and M.A. Maun. 1990. Seed size variation and its effects on seedling growth in Agropyron psammophilum. Botanical Gazette 151:106-113.

Zucconi, F., A. Pera, M. Forte, and M. De Bertolli. 1981. Evaluating toxicity of immature compost. BioCycle 22:54-57. 